\title{
ФИзиология
}

PHYSIOLOGY

DOI: 10.12731/wsd-2017-4-122-133

УДК 612.821:151

\section{ТИПЫ ПРОФИЛЯ \\ МЕЖПОЛУШАРНОЙ ОРГАНИЗАЦИИ ГОЛОВНОГО МОЗГА И ПОКАЗАТЕЛИ ПОТРЕБНОСТИ ОБЩЕНИЯ, ПОТРЕБНОСТИ ДОСТИЖЕНИЯ, БЕСПОКОЙСТВА И ТРЕВОЖНОСТИ СТУДЕНТОВ-МЕДИКОВ І-ІІІ КУРСОВ}

Кононец И.Е., Сайдылдаева А.Б.

Цель. Определение проиентного соотношения вариантов профиля латеральной организации головного мозга; показателей потребности общения, потребности достижения, беспокойства и тревожности студентов-медиков.

Материалы и методы. Метод Е.Д. Хомской, 1997 [19]; схема «рука-нога-глаз-ухо»; методика по Ж. Тейлору, (Н.М. Пейсахов, 1977) [12].

Результаты исследования. Изучены варианты профиля латеральной организащии (ПЛО) головного мозга по схеме "рука-нога-ухо-глаз» и показатели потребности общения (ПО), потребности достижения (ПД), уровень беспокойства и тревоги (БТ) у 320 студентов I-III курсов факультета «Лечебное дело» Кыргызской государственной медииинской академии в возрасте от 18 до 22 лет. Выявлено, что к третьему году обучения увеличиваются варианты с левыми признаками ПЛО у испытуемых. Уровень беспокойства-тревоги (БТ) у первокурсников достоверно выше по сравнению со студентами II-III курсов, причем у девочек показатели БТ достоверно превышают значения у мальчиков. Показатели ПО выше у чистых правшей нежели у смешанных типов ПЛО, а значения ПД самые высокие у смешанных типов ПЛО, чистые правши оказались более тревожны, чем смешанные типы. Результаты исследования мо- 
гут оказать помощь в разработке практических рекомендаций для оптимизациии образовательного проиеесса.

\section{Bвиводы:}

1. К третьему году обучения увеличиваются варианты с левыми признаками профиля латеральной организации мозга у испьтуемых.

2. Показатели беспокойство-тревога на 1 курсе достоверно выше по сравнению со студентами II-III курсов.

3. Показатели потребности общения у чистых правщей превышают значения у лиц со смешанными типами профиля латеральной организации, а потребность достижения выие у смешанных типов ПЛО. Чистыле правши оказались более тревожны, чем смешанные типьл.

Ключевые слова: межполушарная асимметрия; профиль латеральной организащии; потребность общения; достижения; беспокойство; тревожность.

\section{TYPES OF BRAIN INTERHEMISPHERIC ORGANIZATION PROFILE AND INDEX OF DEMAND OF COMMUNICATION, DEMAND OF ACHIEVEMENT, ANXIETY AND APPREHENSION OF STUDENTS-PHYSICIANS I-III COURCES}

\section{Kononez I.E., Saydyldaeva A.B.}

Background: Definition of percentage of profile versions of lateral brain organization; index of demand of communication, demand of achievement, anxiety and apprehension of students - physicians.

Materials and methods: Method of E.D. Homskaya, 1997 [19]; scheme «hand-leg-ear-eye»; methodic on J. Teilor, (N.M. Peisahov, 1977) [12].

Results: Studied profile versions of lateral brain organization (LBO) on the scheme "hand-leg-ear-eye» and index of demand of communication (DC), demand of achievement (DA), level of anxiety and apprehension (AA) of 320 students-physicians of I-III courses of faculty "General medicine» of the Kyrgyz State Medical Academy in the age from 18 to 22. Revealed that to the third year of study increased versions with left signs of LBO with testees. Level of anxiety-apprehension (AA) with the first grade students is truly higher in compare with students of II-III courses, at that index of girls AA truly increases index than boys. Index of DS is higher with only right-handers in compare 
with mixed types of $L B O$, and index of $D C$ are more higher than mixed types of $L B O$, only right-handers are more anxiety than mixed types. Results of research can render assistance in development of practical recommendations for optimization of educational process.

\section{Conclusion:}

1. To the third year of study increased versions with left signs of profile of lateral brain organization with testees.

2. Index of anxiety-apprehension on the 1 grade are truly higher in compare with students of II-III cources.

3. Index of demand of communication with only right-handers increase index with persons with mixed types of profiles of lateral organization, and demand of achievement is higher than mixed types of LBO. Only right-handers are more anxiety than mixed types.

Keywords: interhemispheric asymmetry; profile of lateral organization; demand of communication; achievement; anxiety; apprehension.

\section{Введение}

Функциональная межполушарная асимметрия - одна из наиболее актуальных и широко обсуждаемых проблем в современной науке. По данным российских исследователей динамика межполушарной асимметрии зависит от интенсивности нагрузки. При этом, чем выше интенсивность, тем с большей вероятностью происходит инверсия межполушарных отношений вне зависимости от того, активность какого полушария была выше на момент действия нагрузки $[1,2,3]$. Асимметрия регистрируется и в коре больших полушарий, и в подкорковых структурах [4]. Результаты многочисленных исследований показывают, что высшие отделы (корковые центры) слуховой системы левого и правого полушарий мозга неодинаково участвуют в процессах восприятия, что свидетельствует об асимметрии слуха у человека [5].

По данным ряда авторов, у людей с доминированием левого полушария низкая склонность к депрессии, в отличие от праворуких [6]. Функциональная активность левого полушария обеспечивает угасание, «обтаивание», усреднение и обобщение поступающей информации, а работа правого вносит непредсказуемые трансформации [7].

Исследованиями было показано, что в экстремальных условиях обитания лучше адаптируется пришлое население с правополушарным типом организации головного мозга, в то время как левополушарный тип в подобных условиях подвержен различным заболеваниям [8]. 
В процессе адаптации к новым факторам среды правое полушарие головного мозга становится доминирующим в регуляции различных психофизиологических функций $[9,10]$. Под влиянием специфики учебного процесса и тренировочных воздействий у студентов факультета физической культуры формируется амбидекстральный латеральный фенотип в сравнении с левополушарными студентами других факультетов [11].

Согласно данным авторов высокий уровень ситуативной тревожности выявлен у студентов I курса Казанского федерального университета $[12,13,14,15,16]$. Высокую тревожность преимущественно испытывают студенты Иркутского государственного педагогического колледжа с ведущим левым ухом, правым глазом, правши - профиль ПЛП $(35,7 \%-19,7 \%$, $\mathrm{p}<0,05)$, при этом «левоглазые» студенты (профиль ППЛ) отличаются низким уровнем тревожности [17].

Целью проведенного исследования является определение процентного соотношения вариантов профиля латеральной организации головного мозга, а также показателей потребности общения, потребности достижения, беспокойства и тревожности студентов-медиков.

\section{Материалы и методы исследования}

Обследовано 320 студентов медицинской академии I, II и III курсов в возрасте 18 и 22 лет. Для определения профиля латеральной организации головного мозга у испытуемых использован метод Е.Д. Хомской, 1997 [18]. Асимметрии определяли по схеме «рука-нога-глаз-ухо». Для определения потребности общения (ПО), потребности достижения (ПД) и уровня беспокойства-тревоги (БТ) была использована методика по Ж. Тейлору (Н.М. Пейсахов, 1977) [19].

\section{Результаты исследования и их обсуждение}

В таблице 1 представлены результаты определения профиля латеральной организации головного мозга студентов первого - третьего года обучения.

Таблица 1.

Варианты профиля латеральной организации у студентов I-III курсов

\begin{tabular}{|c|c|c|c|c|c|c|}
\hline курс /ПЛО & \multicolumn{2}{|c|}{ I курс } & \multicolumn{2}{|c|}{ II курс } & \multicolumn{2}{c|}{ III курс } \\
\hline Кол./\% & $\mathrm{n}$ & $\%$ & $\mathrm{n}$ & $\%$ & $\mathrm{n}$ & $\%$ \\
\hline ПППП & 47 & 42,7 & 33 & 44,0 & 31 & 21,8 \\
\hline ППЛП & 20 & 18,2 & 6 & 8,0 & 23 & 16,1 \\
\hline
\end{tabular}


Окончание табл. 1.

\begin{tabular}{|c|c|c|c|c|c|c|}
\hline ПЛПП & 8 & 7,2 & 9 & 12,0 & 8 & 5,6 \\
\hline ЛЛПП & - & - & - & - & 3 & 2,1 \\
\hline ЛЛЛП & - & - & - & - & 4 & 2,8 \\
\hline ЛППП & - & - & 1 & 1,3 & 8 & 5,6 \\
\hline ПППЛ & 11 & 10,0 & 9 & 12,0 & 6 & 4,2 \\
\hline ЛЛПЛ & 2 & 1,8 & - & - & 2 & 1,4 \\
\hline ППЛЛ & 10 & 9,0 & 7 & 9,3 & 6 & 4,2 \\
\hline ЛПЛП & 3 & 2,7 & - & - & 6 & 4,2 \\
\hline ПЛЛП & 3 & 2,7 & 2 & 2,7 & 8 & 5,6 \\
\hline ПЛПЛ & 1 & 0,9 & 6 & 8,0 & 13 & 9,1 \\
\hline ПЛЛЛ & 2 & 1,8 & 1 & 1,3 & 9 & 6,3 \\
\hline ЛЛЛЛ & 3 & 2,7 & - & - & 4 & 2,8 \\
\hline ЛППЛ & - & - & - & - & 2 & 1,4 \\
\hline ЛПЛЛ & - & - & 1 & 1,3 & - & - \\
\hline Всего: & 110 & 100 & 100 & 100 & 110 & 100 \\
\hline
\end{tabular}

Примечание: П-правые, Л-левые показатели латеральной организации головного мозга по схеме: рука-нога-глаз-ухо.

На 1 курсе было 11 вариантов ПЛО, на 3 курсе уже 15 вариантов. На первом году обучения преобладают лица с правым профилем латеральной организации головного мозга, особенно выражена доминанта со стороны правых моторных профилей (рука, нога), причем абсолютное большинство составил вариант ПППП - 42,7\%, ППЛП - все функции правые за исключением глаз выявлен у 18,2\%, чистых левшей (ЛЛЛЛ) оказалось 2,7\%. Среди второкурсников чисто правых профилей было меньше, на 3 курсе определено только $21,8 \%$ чистых правшей. Среди третьекурсников обнаружено достоверное уменьшение доли чистых правшей $(21,8 \%)$ с увеличением лиц с левыми признаками ПЛО (ПЛЛЛ - 6,3\%, ЛЛЛЛ - 2,8\%). Также заметно увеличены различные варианты ПЛО. Появляются смешанные варианты ПЛО (ЛЛПП, ЛЛЛП, ЛППП, ЛПЛП, ПЛЛП, ПЛПЛ).

В этом ключе интересны исследования Г.А. Кураева (1985), который в своих работах указывает, что парциальное доминирование полушарий головного мозга, при котором наблюдается несовпадение ведущей руки и глаза (в отличие от одностороннего), коррелирует с более быстрым созреванием нервных механизмов. У таких людей имеется как бы резерв различных вариантов функционального состояния мозга, что дает более широкие возможности для реализации тех или иных функций. 
В настоящее время твердо установлено, что в экстремальных условиях человек переживает более или менее сильное эмоциональное напряжение, довольно часто проявляющееся как чувство ярко выраженной тревожности, т.е. ожидания возможной неприятности, опасения того, что она может произойти. Показатели беспокойство-тревога - это целый синдром различных проявлений: внешних (в виде нарушения деятельности) и внутренних (изменений вегетативных функций) [21].

Исследование показателей беспокойства-тревоги студентов 1, 2 и 3 курса продемонстрировало, что на 1 курсе они достоверно выше, чем на последующих курсах, причем у девочек БТ выше на первом курсе, чем у мальчиков, ко второму году обучения данные практически выравниваются, к третьему курсу возрастают показатели беспокойства-тревоги у мальчиков и девочек (рис. 1).

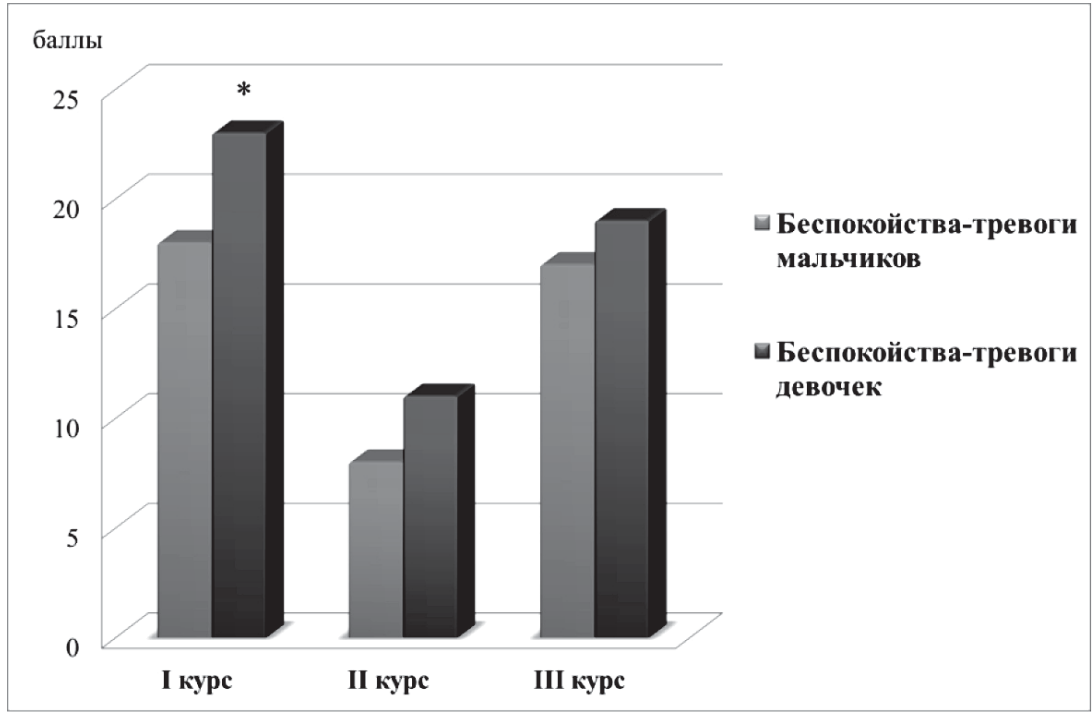

Рис. 1. Показатели беспокойства-тревоги у студентов I-III курсов.

Примечание:* $\mathrm{P}<0,001$ показатель БТ достоверно выше у девочек, чем у мальчиков.

Полученные нами данные сходны с показателями уровня беспокойства-тревоги (далее БТ) студентов Казанского университета: у мужчин исторического факультета - 18,6 баллов, в то время как у женщин - 24,2. У мужчин-математиков уровень БТ - 16,3, у женщин - 22,1, у физиков 
соответствующие показатели равны 17,2 и 19,8. Согласно приведенным результатам БТ у женщин достоверно выше, чем у мужчин [19].

Показатель потребности достижения является одной из мотивационных характеристик, стимулирующих определенный поведенческий акт человека. Потребность общения выявляет степень экстравертированности.

Нами были исследованы психологические показатели потребности достижения (ПД), потребности общения (ПО), а также беспокойство-тревожность (БТ) у чистых правшей, а также у студентов со смешанными профилями ПЛО (рис. 2).

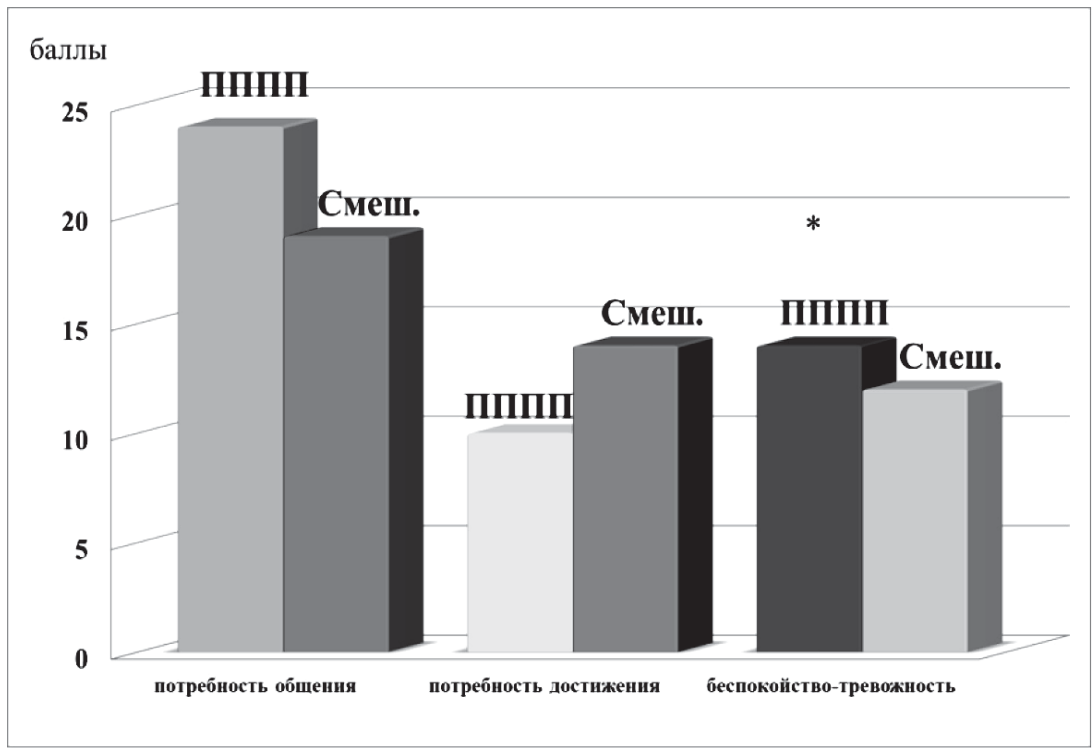

Рис. 2. Показатели ПО, ПД, БТ у студентов с разными профилями МПА.

Примечание:* $\mathrm{P}<0,05$ показатели БТ выше у чистых правшей, чем у смешанных типов.

Потребность общения выше у чистых правшей, что вполне логично, так как доминирование левого полушария, где локализован центр речи, предполагает активность этой функции у правшей. Потребность достижений выше у смешанных типов ПЛО, однако эти данные недостоверны, что свидетельствует о тенденции выявленных изменений. В отношении БТ чистые правши оказались более тревожны, чем смешанные типы $(\mathrm{p}<0,05)$. 
Результаты исследования могут оказать помощь в разработке практических рекомендаций по снижению проявлений утомляемости и нервно-психической напряженности учащихся, в индивидуализации и повышении качества преподавания, что в целом может рассматриваться одним из факторов оптимизации образовательного процесса.

\section{Выводы}

1. К третьему году обучения увеличиваются варианты с левыми признаками профиля латеральной организации мозга у испытуемых.

2. Показатели беспокойство-тревога на 1 курсе достоверно выше, по сравнению со студентами II-III курсов.

3. Показатели потребности общения у чистых правшей превышают значения у лиц со смешанными типами профиля латеральной организации, а потребность достижения выше у смешанных типов ПЛО. Чистые правши оказались более тревожны, чем смешанные типы.

\section{Список литературы}

1. Фокин В.Ф. Динамические свойства функциональной межполушарной асимметрии // Актуальные вопросы функциональной межполушарной асимметрии. Мат. 2-я Всерос. Кон. М., 2003. С. 322-323.

2. Агаджанян, Н.А., Смирнов В.М. Нормальная физиология. М., 2012. 576 с.

3. Фомина Е.В. Роль функциональной асимметрии мозга в успешности адаптации к специфической физической нагрузки // Тезисы докладов IV съезда физиологов Сибири. Новосибирск. 2002. С. 292.

4. Toga A.W., Thompson P.M. Mapping brain asymmetry // Cognitions and emotions. 2003. Vol. 10, pp. 387-420.

5. Auditory corte evored magnrtic fields and lateralization of speech processing / Shtyrov Y., Kujala T., Lyytinen H., Imoniemi R.J., Naatanen R. // Neuroreport. 2000. Vol. 11. № 13, pp. 2893-2896.

6. Psychiatric disorders and left-handedness in children living in an urban environment / Logue D.D., Logue R.T., Kaufmann W.E., Belcher H.M. // Laterality. 2015. Vol. 20. № 2, pp. 249-256.

7. Кроткова О.А. Полушарные механизмы преобразования информации // Асимметрия. 2016. Т.10. № 3. С. 32-34.

8. Межполушарная асимметрия как фактор адаптации человека в условиях Севера / Аршавский В.В., Гельгафт В.С., Ротенберг В.С., Соловенчук Л.Р. // Физиология человека. 1989. Т.15. № 5. С. 142-151. 
9. Колышкин В.В. Роль полушарий головного мозга в регуляции функционального состояния человека // Тезисы докладов IV съезда физиологов Сибири. Новосибирск. 2002. С. 128.

10. Фокин В.Ф., Пономарева Н.В. Энергетическая физиология мозга. М.: Антидор, 2003. 288 c.

11. Эрдынеева К.Г., Попова Р.Э. Функциональная асимметрия мозга как условие адаптации студента к учебной деятельности // Успехи современного естествознания. 2009. М. № 1. С. 64-67.

12. Курчатова А.А., Скурыдина А.С. Тревожность, как состояние психического напряжения студентов в период экзаменационной сессии // Современные наукоёмкие технологии. 2013. № 7-2. С. 211-212.

13. Искакова У.Б., Абшиева 3.С., Журунова М.С. Ситуативная тревожность и психико-эмоциональное состояние студентов во время рубежного контроля // Международный журнал прикладных и фундаментальных исследований. 2016. Т. 11. № 5. С. 900-902.

14. Александров А.Г., Лукьяненок П.И. Изменение уровней тревожности студентов в условиях учебной деятельности // Научное образование. Медицинские науки. 2016. № 6. С. 5-14.

15. Прихожан А.М. Причины, профилактика и преодоление тревожности // Психологическая наука и образование. 2008. № 2. С. 11-17.

16. Шагивалеева Г.Р., Нуриахметова И.Ф. Тревожность детей в дошкольном возрасте // Международный журнал экспериментального образования. 2014. № 6-1. С. 94-94.

17. Финогенко Е.И. Психофизиологическая индивидуальность студентов ССУЗА как фактор адаптации к учебным нагрузкам // Тезисы докладов IV съезда физиологов Сибири. Новосибирск. 2002. С. 291.

18. Нейропсихология индивидуальных различий: Учеб. пособие / Хомская Е.Д., Ефимова И.Е., Будыка Е.Д., Ениколопова Е.В. М. 1997. 281 с.

19. Пейсахов Н.М. Психологические и психофизиологические особенности студентов. Казань, 1977. 295 с.

20. Кураев Г.А. Межполушарная асимметрия нейрональной активности мозга кошки // Сенсорные системы. Сенсорные процессы и асимметрия полушария. Л. 1985. С. 75-87.

21. Harburg E., Roeper R., Ozgoren F. et al. Handedness and temperament // Pest. and Mot. Skills. 1981, pp. 52-59.

\section{References}

1. Fokin V.F. Dinamicheskie svojstva funkcional'noj mezhpolusharnoj asimmetrii [Dynamic qualities of functional interhemisperic asymmetry]. Aktual'nye 
voprosy funkcional'noj mezhpolusharnoj asimmetrii. Mat. 2-ja Vseros. konf. Moscow, 2003, pp. 322-323.

2. Agadzhanjan, N.A., Smirnov V.M. Normal'naja fiziologija. [Normal physiology]. Moscow, 2012. p. 576.

3. Fomina E.V. Rol' funkcional'noj asimmetrii mozga $v$ uspeshnosti adaptacii $\mathrm{k}$ specificheskoj fizicheskoj nagruzki [Role of functional brain asymmetry in success of adaptation to specific physical load]. Tezisy dokladov IV s\#ezda fiziologov Sibiri. Novosibirsc. 2002. P. 292.

4. Toga A.W., Thompson P.M. Mapping brain asymmetry. Cognitions and emotions. 2003, issue 10, pp. 387-420.

5. Auditory corte evored magnrtic fields and lateralization of speech processing. Shtyrov Y., Kujala T., Lyytinen H., Imoniemi R.J., Naatanen R. Neuroreport. 2000, vol. 11, no 13, pp. 2893-2896.

6. Psychiatric disorders and left-handedness in children living in an urban environment. Logue D.D., Logue R.T., Kaufmann W.E., Belcher H.M. Laterality. 2015, vol. 20, no 2, pp. 249-256.

7. Krotkova O.A. Polusharnye mehanizmy preobrazovanija informacii [Hemispheric mechanisms of information generation]. Journal of asymmetry. 2016, vol. 10, no 3, pp. 32-34.

8. Arshavskij V.V., Gel'gaft V.S., Rotenberg V.S., Solovenchuk L.R. Mezhpolusharnaja asimmetrija kak faktor adaptacii cheloveka v uslovijah Severa [Interhemispheric asymmetry, as a factor of human adaptation in conditions of the North]. Fiziologija cheloveka [Human Physiology], 1989, vol.15, no 5, pp. 142-151.

9. Kolyshkin V.V. Rol' polusharij golovnogo mozga v reguljacii funkcional'nogo sostojanija cheloveka [Role of hemispheric of brain in regulation of functional human condition]. Tezisy dokladov IV s\#ezda fiziologov Sibiri. Novosibirsc, 2002, P. 128.

10. Fokin V.F., Ponomareva N.V. Jenergeticheskaja fiziologija mozga. [Energetic brain physiology]. Moscow: Antidor Publ., 2003, P. 288.

11. Jerdyneeva K.G., Popova R.Je. Funkcional'naja asimmetrija mozga kak uslovie adaptacii studenta $\mathrm{k}$ uchebnoj dejatel'nosti [Functional asymmetry of brain as a condition of student adaptation to the academic activity]. Uspehi sovremennogo estestvoznanija [Scientific journal "Advances in current natural sciences"], 2009, issue 1, pp. 64-67.

12. Kurchatova A.A., Skurydina A.S. Trevozhnost', kak sostojanie psihicheskogo naprjazhenija studentov $\mathrm{v}$ period jekzamenacionnoj sessii [Anxiety as a condition of psychic strain of students in the period of examination session]. 
Sovremennye naukojomkie tehnologii [Scientific journal "Modern high technologies"], 2013, issue 7-2, pp. 211-212.

13. Iskakova U.B., Abshieva Z.S., Zhurunova M.S. Situativnaja trevozhnost' i psihiko-jemocional'noe sostojanie studentov vo vremja rubezhnogo kontrolja [Situative anxiety and psychic - emotional condition of students during the Midterm Examination]. Mezhdunarodnyj zhurnal prikladnyh i fundamental'nyh issledovanij, 2016, vol. 11, no 5, pp. 900-902.

14. Aleksandrov A.G., Luk'janenok P.I. Izmenenie urovnej trevozhnosti studentov $\mathrm{v}$ uslovijah uchebnoj dejatel'nosti [Change of anxiety levels of students in conditions of academic activity]. Nauchnoe obrazovanie. Medicinskie nauki, 2016, issue 6, pp. 5-14.

15. Prihozhan A.M. Prichiny, profilaktika i preodolenie trevozhnosti [Reasons, proficiency and overruling of anxiety]. Psikhologicheskaya nauka i obrazovanie [Psychological Science and Education], 2008, inssue 2, pp. 11-17.

16. Shagivaleeva G.R., Nuriahmetova I.F. Trevozhnost' detej v doshkol'nom vozraste [Anxiety of children in preschool age]. Mezhdunarodnyj zhurnal jeksperimental'nogo obrazovanija, 2014. Inssue 6-1, pp. 94.

17. Finogenko E.I. Psihofiziologicheskaja individual'nost' studentov SSUZA kak faktor adaptacii k uchebnym nagruzkam [Psychophysiological individuality of students of SSUZA as a factor of adaptation to academic loads] Tezisy dokladov IV s\#ezda fiziologov Sibiri. Novosibirsk, 2002. P. 291.

18. Homskaja E.D., Efimova I.E., Budyka E.D., Enikolopova E.V. Nejropsihologija individual'nyh razlichij: Ucheb. posobie [Neuropsychology of individual differences, Study guide], Moscow. 1997. P. 281.

19. Pejsahov N.M. Psihologicheskie i psihofiziologicheskie osobennosti studentov. [Physiological and psychophysiological particulars of students]. Kazan, 1977. $295 \mathrm{p}$.

20. Kuraev G.A. Mezhpolusharnaja asimmetrija nejronal'noj aktivnosti mozga koshki. Sensornye sistemy. Sensornye processy i asimmetrija polusharija [Interhemisphere asymmetry of neuronal activity of brains of cat. Sensor systems. Sensor processes and asymmetry of hemisphere]. L.1985, pp. 75-87.

21. Harburg E., Roeper R., Ozgoren F. et al. Handedness and temperament. Pest. and Mot. Skills. 1981, pp. 52-59.

\section{ДАННЫЕ ОБ АВТОРАХ}

Кононец Ирина Евгеньевна, д.м.н., профессор, заведующая кафедрой фундаментальной и клинической физиологии им. С.Б. Даниярова Кыргызская государственная медииинская академия им. И.К. Ахунбаева 
ул. Ахунбаева, 92, г. Бишкек, 720020, Кыргызская Республика ikononecz@mail.ru

Сайдылдаева Аида Бейшеналиевна, к.м.н., доцент кафедры фундаментальной и клинической физиологии им. С.Б. Даниярова Кыргызская государственная медичинская академия им. И.К. Ахунбаева ул. Ахунбаева, 92, г. Бишкек, 720020, Кыргызская Республика bbaassdd@mail.ru

DATA ABOUT THE AUTHORS

Kononez Irina Evgen'evna, MD, Professor, Head of the Department of Fundamental and Clinical Physiology

Kyrgyz State Medical Academy named after I.K. Akhunbayeva 92, Akhunbaev Str., Bishkek, 720020, Kyrgyz Republic ikononecz@mail.ru SPIN-code: 7582-9788

Saydyldaeva Aida Beyshenalievna, Ph.D., Associate Professor of the Department of Fundamental and Clinical Physiology Kyrgyz State Medical Academy named after I.K. Akhunbayeva 92, Akhunbaev Str., Bishkek, 720020, Kyrgyz Republic bbaassdd@mail.ru SPIN-code: 9100-1738 